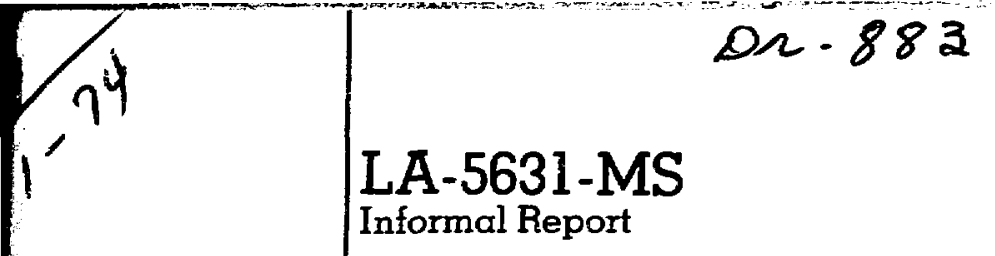

UC-38

Reporting Date: May 1974 Issued: June 1974

\title{
Methods of Energy Transfer from a Magnetic Energy Storage System Using a Transfer Capacitor and a Superconducting Switch
}

by

D. M. Weldon

J. D. G. Lindsay

\section{scientific laboratory}

of the University of California

LOS ALAMOS, NEW MEXICO 87544

$\downarrow 1$ 
This report was prepared as an account of work sponsored by the United States Government. Neither the United States nor the United States Atomic Energy Commission, nor any of their employees, nor any of their contractors, subcoritractors, or their employees, makes any warranty, express or implied, of assumes any legal liability or responsibility for the accuracy. completeness or usefulness of any information, apparatus, product or process dis. closed, or represents that its use would not infringe privately owned rights.

In the interest of prompt distribution. this LAMS report was not edited by the Technical Information staff.

Prinled in the United States of America. Available from National Technical Information Service

U.S. Department of Comnerce 5285 Port Royal Road Springlielo', Virginic 22151

Price: Printed Copy $\$ 4.00$ Microfiche S1.45 
This report was ptepared as an account of work consored by the Uniled States Gatemmear. Neither the Uniled States nor the Unised States Atomic Enersy Commiscion, nor any of thei employees, not eny of their contraesors, subeontractors, of ibei exployecs. makes any warranty, enoress or implied, or axumes any lees liabitity or responsibility for the accuracy, com. pleteness or usefulness of any information, appuratus, product or process disctosed, ur gepresents that its use would not infringe primlety owned rights.

METHODS OF ENERGY TRANSFER FROA A MAGAETIC EIERGY STORAGE SYSTEN

USING A TRANSFER CAPACITOR ARD A SUPERCONDUCTIRG SWITCH

by

D. M. Weldon and J. D. G. Lindsay

\section{ABSTRACT}

Three circuits for magnetic cnergy storage using a transfer capacftor and a superconducting suitch are analyzed, and a set of cquations are derived thich can be used for paraeter studies of these circuits.

\section{INTRODUCTION}

Large magnetic energy storage systems making use of superconducting storage coils and superconducting suitches have been considered for use in a future generation of $\theta$-pinch plasma experiments. 1,2 The circuit usually considered is shown in Fig. 1. The operational sequence for this storage system cal2s for building up current in coll $L_{P}$ and suitch $R_{\text {SW }}$ while they are both in the superconducting state. To release the stored energy, the switch is driven nozwal by means of some auxiliary circuitzy. The sudden appearance of resistance in the suttch causes current to decay in the primary circuit. As the primary current decays energy is coupled inductively into the secondary $L_{S}$, which in turn drives experiment $L_{C}$. This cixcuit suffers from the disadvantage that at best only 257. of the stored energy

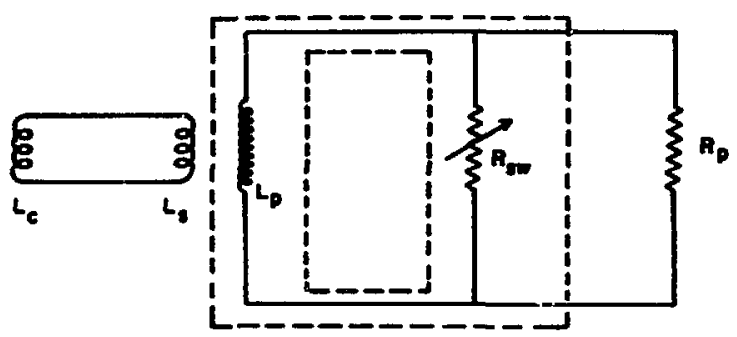

Fig. 1. Schematic representation of a magnetic energy storage system. Cryogenic regions are enclosed in dashed lines. is delivered to $L_{C}$, while $50 \%$ of the stored energy is dissipated in resistors $R_{P}$ and $R_{S W^{*}}$ Efficlency of energy transfer can be great $2 y$ increased by Enserting a capacfor across the circuit in any of the ways shown in Fig. 2. In order to understand the operation of these circuits, consider circuit (a) with $L_{B}=L_{E}$ and a persistent
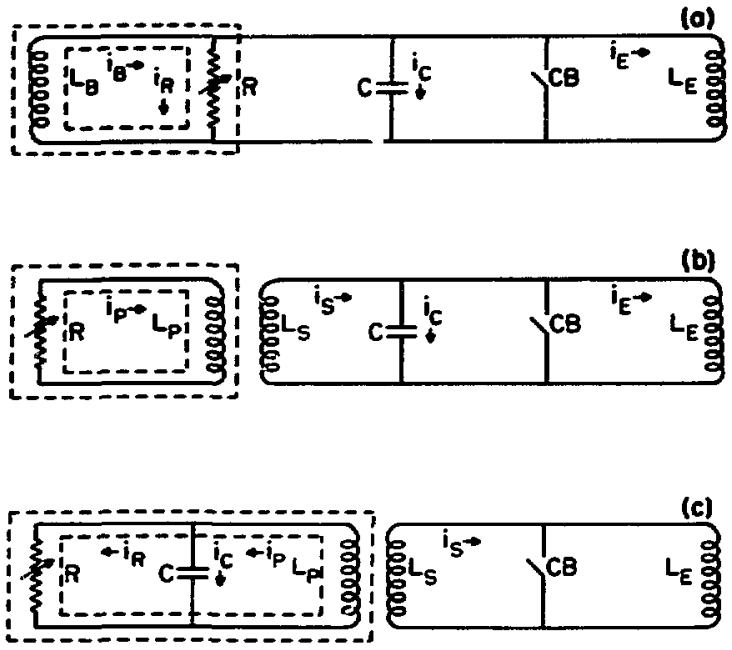

Fig. 2. Magnetic energy storage circuits using trans fer capacitors. 
current flowing through superconducting elements $I_{B}$ and $R$. Then switch $R$ is driven normal a voltage builds up across $R$, and as shown in Fig. 3 , this causes current both to build up in $L_{E}$ and to flow into capacitor $C$. After reaching a peak voltage, capacitor $C$ begins to discharge and current flows from the capacitor increasing tine current in $L_{E}$ and further decreasing the current in $L_{B}$ * In the limit that $R$ is infinite, the current in $I_{B}$ eventually becomes zero and the current in $i_{E}$ equals the current originally in $L_{B}$. Crowbar switch $C B$ is then closed and current flows through load $\operatorname{col} 1 \mathrm{~L}_{E}$ and switch CB until damped out by stray resistance. In the transformer coupled systems current wavefortas

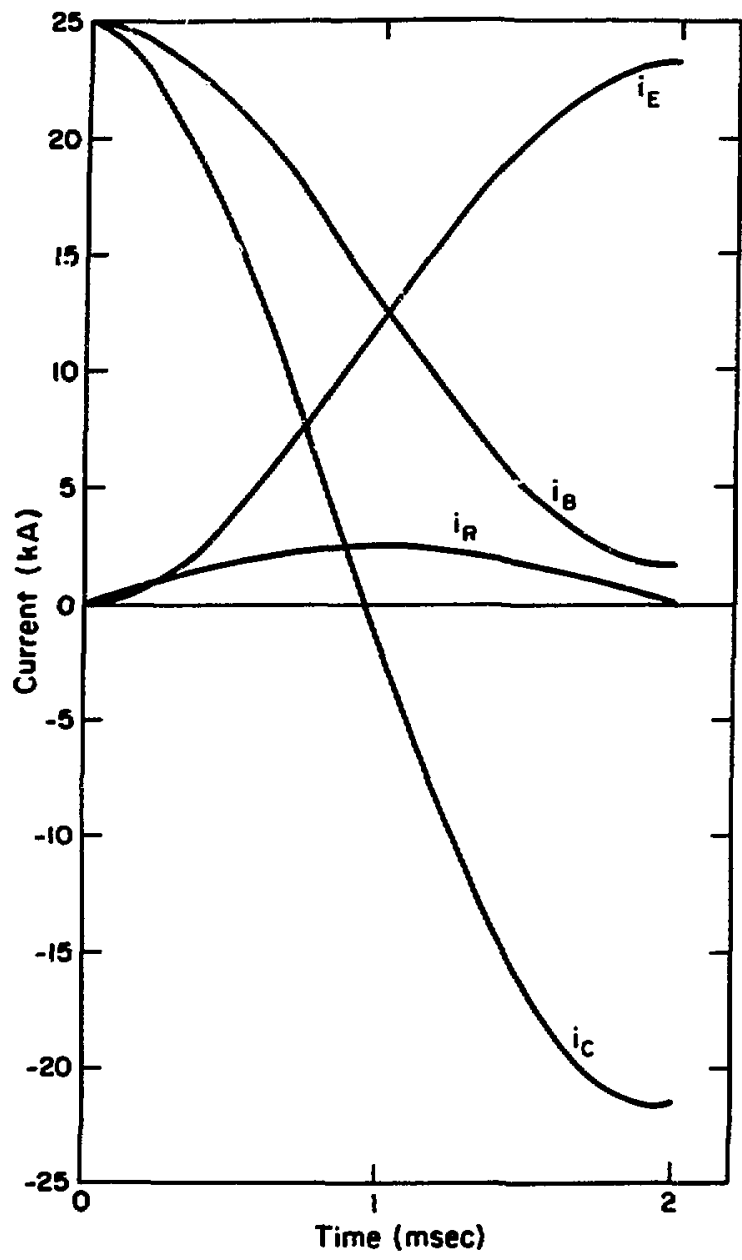

Fig. 3. Current in the circuit elements as a function of time for a direct coupled magnetic energy storage system using a transfer capacitor. Circuit parameters are $R=16 \Omega, I_{B}=25 \mathrm{kA}, L_{B}=L_{E}=2 \mathrm{mH}$, $\mathrm{C}=400 \mu \mathrm{F}$. are similar although there are some additional effects if the coupling between secondary and primary is less than perfect $(k<1)$. The capacitor size is considerable in all cases, since at peak voitage it nust store about $1 / 2$ of the energy originally in the storage coil.

Circuit analysis has been carried out by Carruthers $^{3}$ for case (a) of Fig. 2 in a system switched by mechanical switches and ignitrons. Resistance of the mechanical switch replacing $R$ was assumed to be infinite and the opening instantaneous. In this report we will analyze this circuit using a superconducting switch wich has a finite resistance when open although it may still be thought of as opening instantaneously. We will also extend resuits to the transformer coupled circuits of Fig. 2, including the situation in wtich the coupling is less than per fect.

\section{IT. PARAYETERS FIXED BY THE PLASHA EXPERIHENT}

As far as the angnetic energy storage system is cencerned, the plasna experiment may be thought of as only a large multi-turn toroidal solenold with a $28.6 \mathrm{~m}$ major radius and a $16 \mathrm{~cm}$ minor radius. Other details such as the shock heating apparatus, vacuum system, stabilizing windings, etc., can be 1gnored. Risetime of the magnetic field in the experiment is designated by $T$ and has a value of 1 msec. Peak field in the experiment coil is $60 \mathrm{kG}$. The energy storage cofl. is a second torus set next to the experiment and having a slightly different major radius so it does not intersect the expeziment. Both the experiment and storage coll are modulartzed for convenience of construction and maintenance, and to limft the voltage seen across the coil leads. Since the experiment and storage coll, as well as the transformer secondary if there is onc, have almost the same major radius, the module length will be considered the sane for all three coils. Calculations will be made for one of the modules, and because of the corotdal shape of the final configuracion the long solenold formulas for magnecte field and Inductance can be safely used. Inductance of a long solenold in henries is given by

$$
L=4 n^{2} \times 10^{-9} \frac{n^{2} r^{2}}{l}
$$


where $n$ is the total number of turns in a coil module, $r$ is the coil radius in $\mathrm{cm}$, and $\&$ is the module length in $\mathrm{cm}$. Using the radius of the compression coil this can be written as

$$
L_{E}=F \frac{n_{E}^{2}}{\ell} \text {, }
$$

with $\xi=1.01 \times 10^{-5} \mathrm{n}-\mathrm{cm} / \mathrm{turn}^{2}$. Energy in joules stored in the magnetic field of a solenoid is given by

$$
W=10^{-7} \frac{r^{2} \ell B^{2}}{8} \text {, }
$$

where $B$ is the magnetic field in gauss. Using the radius and magnetic field of the experiment, this can be written as

$$
W_{E}=\eta \hat{l} \text {, }
$$

where $\eta_{1}=1.15 \times 10^{4} \mathrm{~J} / \mathrm{cm}$.

III. DIRECT COUPLING OF STORAGE COIL AND EXPERINENT A. Currents in the circuit Elements

The network equations for circuit (a) of Fig. 2 can be written as:

$L_{B} \frac{d i_{B}}{d C}+i_{R} R=0$ ，

$L_{B} \frac{d i_{B}}{d t}+L_{E} \frac{d i_{E}}{d t}=0$,

C $I_{B} \frac{d^{2} i_{B}}{d t^{2}}+i_{B}-I_{R}-i_{E}=0$.

Appropriate infial values at $t=0$ are: $i_{B}=I_{B}$, $f_{E}=0, \frac{d t_{B}}{d t}=\frac{d i_{E}}{d t}=\frac{d i}{d t}=0$.

Using these initial values the network equaticns have the solution:

$I_{E}=I_{B} \frac{I_{H}}{L_{y}+I_{E}}\left(1-e^{-\gamma t} \cos +t-\frac{Y}{W} c^{-Y t} \sin . t 5\right)$,

$$
\begin{gathered}
i_{B}=I_{B} \frac{L_{E}}{L_{B}+L_{E}}\left(\frac{L_{B}}{L_{E}}+e^{-\gamma t} \cos \omega t+\frac{\gamma}{\omega} e^{-\gamma t} \sin \omega t\right),(6) \\
i_{C}=I_{B}\left(e^{-\gamma t} \cos \omega t-\frac{\gamma}{\omega} e^{-\gamma t} \sin \omega t\right) \\
i_{R}=2 I_{B} \frac{\gamma}{\omega} e^{-\gamma t} \sin \omega t,
\end{gathered}
$$

where

$$
\gamma=\frac{1}{2 R C} \text {, }
$$

$$
x=\sqrt{\frac{1}{L_{T} C}-\gamma^{2}},
$$

and

$$
L_{T}=\frac{L_{E} L_{E}}{L_{E}+L_{E}}
$$

B. Times of Peak Voltage and Crowbar Application

The crowbar time is one of the known input parameters $(\tau)$, and the crowbar is applied when $i_{E}$ is a maximum. Substitution of $t=T$ in the expression for $\frac{d i_{E}}{d t}=0$ gives

$$
w=\frac{\bar{i}}{i}
$$

For any practical energy storage system the damping which occurs before the crowbar is applied must be small, and this can be ensured by demanding $\frac{\omega}{\gamma} \gg 1$. We define the quantity $\beta$ by

$$
\beta=\frac{w}{\gamma}
$$

Parameter $\beta$ is another of the known input parameters and we assume $\beta \geq 10$. In sane of the expressions to be derived, $\beta^{-1}$ will be used as an expansion parameter and results will be carried out to order $\beta^{-2}$. Peak voltage across $C$ (or $R$ ) occurs when $\frac{d i_{R}}{d t}=0$ and this expression gives the equation

$$
\cot \left(\frac{\pi}{2}-1=t v c\right)=\beta
$$


Fron the expansion

$$
\cot ^{-1} \beta=\frac{1}{\beta}-\frac{1}{3 \beta^{3}}+\frac{1}{5 \beta^{5}}-\frac{1}{7 \beta^{7}}+\cdots,
$$

we find that to order $\frac{1}{\beta^{2}}$

$$
t_{v C}=\frac{T}{2}\left(1-\frac{2}{\pi \beta}\right)
$$

Peak energy in $\mathrm{L}_{\mathrm{E}}$ is given by

$$
W_{E}=\frac{1}{2} T_{E} T_{E}^{2}
$$

where $I_{E}$ is the peak current in $I_{E}$. Similarly the energy originally stored in $I_{B}$ is

$$
W_{B}=\frac{1}{2} I_{B} I_{B}^{2}
$$

Their ratio is

$$
\frac{W_{E}}{W_{B}}=\frac{\frac{L_{E}}{L_{B}}}{\left(1+\frac{L_{E}}{L_{B}}\right)^{2}}\left(1+e^{\left.-\frac{\pi}{\beta}\right)^{2}}\right.
$$

Then for any $\beta$ the maximum energy transfer will occur when

$$
\mathbf{L}_{\mathbf{E}}=\mathrm{L}_{\mathbf{B}} \text {, }
$$

and we will require that $I_{E}=I_{B}$ for the rest of the calculation.

c. Values of $R, C, L_{E}$, and $I_{E}$

Two more input parameters must now be chosen and those selected are $I_{B}$ (the current in $L_{B}$ at $t=0$ ), and $v_{C}$ (the peak voltage across the network). From

$$
v_{c}=\frac{1}{c} \int_{0}^{t} i_{c} d t
$$

and the integrals

$$
\begin{aligned}
& \int e^{-\gamma t} \cos \omega t=\frac{e^{-\gamma t}}{\gamma^{2}+\omega^{2}}(-\gamma \cos \omega t+\omega \sin \omega t) \\
& \int e^{-\gamma t} \sin \omega t=-\frac{e^{-\gamma t}}{\gamma^{2}+\omega^{2}}(\gamma \sin \omega t+\sin \omega t),
\end{aligned}
$$

the result obtained is

$$
\begin{aligned}
& V_{C}=\frac{I_{B}}{C \omega} e^{-\left(\frac{\pi}{2 \beta}-\frac{1}{\beta^{2}}\right)} \cos \left(\frac{1}{\beta}\right) \\
& C=\frac{I_{B}{ }^{\top}}{V_{C^{\pi}}}\left[1-\frac{\pi}{2 \beta}+\left(\frac{\pi}{8}+\frac{1}{2}\right) \frac{1}{\beta^{2}}\right] .
\end{aligned}
$$

Resistor $R$ can be found by substituting Eq. (18) into Eq. (9), and the result is

$$
R=\frac{V_{c}}{2 I_{B}} \beta\left[1+\frac{\pi}{2 \beta}+\left(\frac{\pi^{2}}{8}-\frac{1}{2}\right) \frac{1}{\beta^{2}}\right] .
$$

Inductance $\mathrm{L}_{\mathrm{E}}$ is found from substituting Eqs. (11), (12), (17), and (18) into Eq. (10). The result is

$$
I_{E}=L_{B}=\frac{2 \pi V_{C}}{\pi I_{B}}\left[1+\frac{\pi}{2 \beta}+\left(\frac{\pi}{8}-\frac{3}{2}\right) \frac{1}{\beta}\right] .
$$

Peak current $I_{E}$ cones from substituting $\tau=\frac{\pi}{\omega}$ into Eq. (5) and the result is

$$
I_{E}=I_{B}\left(1-\frac{\pi}{2 \beta}+\frac{\pi^{2}}{4 \beta^{2}}\right) .
$$

\section{Energy Dissipation and Efficiency}

From Eqs. (16) and (20) the energy stored originally is

$$
W_{B}=\frac{\pi V_{C} I_{B}}{\pi}\left[1+\frac{\pi}{2 \beta}+\left(\frac{\pi}{8}-\frac{3}{2}\right) \frac{1}{\beta^{2}}\right] .
$$

Similarly Eqs. (15) and (20) give

$$
W_{E}=\frac{\pi V_{C} I_{B}}{\pi}\left[1-\frac{\pi}{2 \beta}+\left(\frac{3 \pi^{2}}{8}-\frac{3}{2}\right) \frac{1}{\beta^{2}}\right] .
$$


$\left(Q_{R}\right)$ is found by substituting Eq. (19) into

$$
\begin{aligned}
Q_{R} & =R \int_{0}^{T} i_{R}^{2} d t \\
& =I_{B} V_{C^{\top}}\left(\frac{1}{\theta}-\frac{\pi}{2 \beta^{2}}\right) .
\end{aligned}
$$

At $t=\tau$ no energy is left in capacitor $C$ since the voltage across $C$ is zero $\left(\frac{d i_{E}}{d t}=0\right)$. However, there is a small amount left in $L_{B}$ which we ca11 $Q_{B}$.

$$
\begin{aligned}
Q_{B} & =\frac{1}{2} L_{B}{ }^{2}{ }^{2}(t=\tau) \\
& =\frac{\pi}{4} \tau V_{C_{B}} \frac{1}{{ }^{2}}
\end{aligned}
$$

Notice that $Q_{B}$ is an order of magnitude smaller than $Q_{R}$. As a consistency check the energy conservation equation,

$$
W_{B}=W_{E}+Q_{R}+Q_{B}
$$

can be seen to be satisfied through order $\beta^{-2}$. Defining the efficiency by

$$
\epsilon=\frac{W_{E}}{W_{B}},
$$

and substituting Eqs. (22) and (23) gives

$$
\varepsilon=1-\frac{\pi}{\beta}+\frac{3 \pi^{2}}{4 \beta^{2}}
$$

\section{E. Module Length, Number of Turns, and Magnetic \\ Eie 1d Strength}

As has been mentioned, the module length for $L_{E}$ and $L_{B}$ is assumed to be the same and is found from Eqs. (4) and (23).

$$
\ell=\frac{V_{C} I_{B}{ }^{2}}{\pi}\left[1-\frac{\pi}{2 \beta}+\left(\frac{3 \pi}{8}-\frac{3}{2}\right) \frac{1}{\beta^{2}}\right] \text {. }
$$

Equations (2), (20), and (28) determine the number of turns on each module of the experiment coil.

$$
n_{E}=\frac{\pi V_{C}}{\pi} \sqrt{\frac{2}{\eta E}}\left[1+\left(\frac{\tau^{2}}{8}-\frac{3}{2}\right) \frac{1}{\beta^{2}}\right] .
$$

One more input parameter must be chosen to fix the number of turns and peak magnetic field in the storage coil. The radius of the storage coil in cril $\left(r_{B}\right)$ is the chosen parameter. Equation (3) applied to the storage coil yields the magnetic field in gauss.

$$
B_{B}=\frac{\sqrt{8 \times 10^{7}}}{r_{B}}\left(1+\frac{\pi}{2 \beta}\right) \text {. }
$$

The number of turns on the storage coil is then calculated from

$$
B_{B}=\frac{2 \pi}{5} \frac{n_{B}{ }_{B}}{\ell}
$$

We obrain

$$
n_{B}=\frac{10^{4} / 5}{\pi^{2}} \frac{v_{C} C^{\top}}{r_{B} / \pi}\left[1+\left(\frac{\pi^{2}}{8}-\frac{3}{2}\right) \frac{1}{\beta^{2}}\right] .
$$

\section{F. Method for Obtaining Approximate Results}

Approximate expressions for all the equations just laborious $1 \mathrm{y}$ derived can be found simply by assuming $t_{V c}=\tau / 2$ and setting $e^{-\gamma t}=1$ when calculating the various circuit parameters from Eqs. (5) through (8). This is equivalent to taking only the zero order terms in most of the expansions. For $\beta \geq 20$, errors $\leq 8 \%$ will be made in $L_{E}, R, I_{E}$, and $c$. The dissipation $Q_{R}$ will be $\leq 8 \%$ too large, but the efficiency will be correct through order $\beta^{-1}$.

\section{G. Sumary}

Table I summarizes the quantities which have been calculated from the given set of input parameters. These input parameters are: the initial current in the storage coil in amperes $\left(I_{B}\right)$, the radius of the storage coil in $\mathrm{cm}\left(r_{B}\right)$, the peak voltage across tir? network in volts $\left(V_{C}\right)$, the tranifer time to the experiment in seconds $(\tau)$, the ratio of the damping constant to angular frequency $(\beta)$, the energy cielivered to the experiment per unit length in $\mathrm{J} / \mathrm{cm}$ (i), and an inductance constant for the experiment coil in $\mathrm{H}-\mathrm{cm} / \operatorname{turn}^{2}$ ( $\xi$ ). This latter constant depends only on the coil radius. 
CALCULATEd PARAMETERS FOR A DIRF.CT COUPLED MAGNETIC ENERGY STORAGE SYSTEM

Parameter

Time of peak voltage (sec)

Capacitance (F)

Resistance $(\Omega)$

Inductance (H)

Peak Current in $L_{E}(A)$

Energy transferred to $L_{E}(J)$

Energy lost in $R$ up to $t=\tau(J)$

Energy stored in $\mathrm{I}_{B}(\mathrm{~J})$

Energy left in $I_{B}$ at $t=T(J)$

Efficiency

Module length $(\mathrm{cm})$

Number of turns on $L_{E}$

Number of turns on $L_{B}$

Field of $L_{B}$ (G)
Equation

$t_{v C}=\frac{\pi}{2}\left(1-\frac{2}{\pi \beta}\right)$

$c=\frac{I_{B}{ }^{\top}}{\pi V_{C}}\left[1-\frac{\pi}{2 \beta}+\left(\frac{\pi^{2}}{8}+\frac{1}{2}\right) \frac{1}{\beta^{2}}\right]$

$R=\frac{V_{C}^{\beta}}{2 I_{B}}\left[1+\frac{\pi}{2 \beta}+\left(\frac{\pi^{2}}{8}-\frac{1}{2}\right) \frac{1}{\beta^{2}}\right]$

$\mathrm{L}_{\mathrm{B}}=\mathrm{L}_{\mathrm{E}}=\frac{2 \pi \mathrm{V}_{\mathrm{C}}}{\pi \mathrm{I}_{\mathrm{B}}}\left[1+\frac{\pi}{2 \beta}+\left(\frac{\pi^{2}}{8}-\frac{3}{2}\right) \frac{1}{\beta^{2}}\right]$

$I_{E}=I_{B}\left(1-\frac{\pi}{2 \beta}+\frac{\pi^{2}}{4 \beta^{2}}\right)$

$W_{E}=\frac{\tau V_{C} I_{B}}{\pi}\left[1-\frac{\pi}{2 \beta}+\left(\frac{3 \pi^{2}}{8}-\frac{3}{2}\right) \frac{1}{\beta}\right]$

$Q_{R}=I_{B} V_{c} T\left(\frac{l}{\beta}-\frac{\pi}{2 \beta^{2}}\right)$

$W_{B}=\frac{\pi V_{C^{I} B}}{\pi}\left[1+\frac{\pi}{2 \beta}+\left(\frac{\pi^{2}}{8}-\frac{3}{2}\right) \frac{1}{\beta^{2}}\right]$

$Q_{B}=\frac{\pi T V_{C} I_{B}}{4 \beta^{2}}$

$\epsilon=1-\frac{\pi}{\beta}+\frac{3 \pi^{2}}{4 \beta^{2}}$

$\ell=\frac{V_{C} I_{B} \tau}{\pi \eta}\left[1-\frac{\pi}{2 \beta}+\left(\frac{3 \pi^{2}}{8}-\frac{3}{2}\right) \frac{1}{\beta^{2}}\right]$

$n_{E}=\frac{\pi V_{C}}{\pi} \sqrt{\frac{2}{\eta_{1}}}\left[1+\left(\frac{\pi^{2}}{8}-\frac{3}{2}\right) \frac{1}{\beta^{2}}\right]$

$n_{B}=\frac{10^{4} \sqrt{5}}{\pi^{2}} \frac{v_{C}}{r_{B} \sqrt{7}}\left[1+\left(\frac{\pi^{2}}{8}-\frac{3}{2}\right) \frac{1}{B^{2}}\right]$

$B_{B}=\frac{\sqrt{8 \times 10^{7} \eta}}{r_{B}}\left(1+\frac{\pi}{2 B}\right)$ 
IV. TRANSFORMER COUPLING OF STORAGE COIL AND EXPERIMENT WITT A TRANSFER CAPACITOR ACROSS THE TRANSFORMER SECONDARY

\section{Currents in the Circuit Elements}

1. Network Equations. The network equation

for circuit (b) of Fig. 2 can be written as:

$$
\begin{aligned}
& L_{P} \frac{d i_{P}}{d t}+k / I_{P} \bar{L}_{S} \frac{d i_{S}}{d t}+i_{P} R=0, \\
& L_{S} \frac{d i_{S}}{d t}+L_{E} \frac{d i_{E}}{d t}+k \sqrt{L_{P} \bar{L}_{S}} \frac{d i_{P}}{d t}=0, \\
& C L_{E} \frac{d^{2} i_{E}}{d t^{2}}+i_{E}-i_{S}=0 .
\end{aligned}
$$

If $k=1$, solution of these equations reguires solving a second order differential equation, but if $k<1$ the differential equation is third order. We take the general case $k \leq 1$ and rewrite Eqs. (33) as

$$
\begin{aligned}
& D i_{P}=0, \\
& D i_{E}=\frac{k R I_{P} \sqrt{I_{P} L_{S}}}{C_{E}} \\
& D i_{S}=\frac{k R I_{P}}{C} \sqrt{L_{P} L_{S}}\left(\frac{1}{L_{T}}-\frac{1}{L_{S}}\right),
\end{aligned}
$$

where

$$
\begin{aligned}
D & =I_{P} L_{S}\left(1-k^{2}\right) \frac{d^{3}}{d t^{3}}+R L_{S} \frac{d^{2}}{d t^{2}} \\
& +\left[\frac{k^{2} L_{P}}{C}+\frac{L_{P} L_{S}}{C L_{T}}\left(1-k^{2}\right)\right] \frac{d}{d t}+\frac{R L_{S}}{C L_{T}},
\end{aligned}
$$

and

$$
\mathbf{L}_{T}=\frac{\mathbf{L}_{S} L_{E}}{L_{S}+L_{E}}
$$

The quantity $I_{P}$ is the current in $I_{P}$ at $t=0$. We define the parameters $\alpha$ and $\rho$ by

$$
\alpha=\mathrm{k}^{2} \frac{\mathrm{L}_{\mathrm{P}}}{\mathrm{L}_{\mathrm{S}}} \text {, }
$$

and

$$
\rho=\frac{R}{L_{\mathbf{P}}\left(1-\mathrm{k}^{2}\right)} \text {. }
$$

The proper initial values at $t=0$ for Eqs. (33) through (36) are $i_{P}=I_{P}, i_{S}=i_{E}=0$,

$\frac{d i_{P}}{d t}=-I_{P} \rho, \frac{d i_{S}}{d t}=\sqrt{2} I_{P} \rho, \frac{d i_{E}}{d t}=0, \frac{d^{2} i_{P}}{d t^{2}}=I_{P} \rho^{2}$, $\frac{d^{2} i}{d t^{2}}=-\sqrt{\alpha^{2}} I_{P}$, and $\frac{d^{2} i_{E}}{d t^{2}}=0$.

2. Solution of a Cubic Equation. ${ }^{4}$ The auxiliary equation connected with Eqs. (34) through (36) will be a cubic equation with one real root and two complex roots. If the auxiliary cubic equation is

$$
z^{3}+a_{2} z^{2}+a_{1} z+a_{0}=0
$$

and we define

$$
\begin{aligned}
& q=\frac{1}{3} a_{1}-\frac{1}{9} a_{2}{ }^{2}, \\
& r=\frac{1}{6}\left(a_{1} a_{2}-3 a_{0}\right)-\frac{1}{27} a_{3}{ }^{2},
\end{aligned}
$$

$$
s_{1}=\left[r+\left(q^{3}+r^{2}\right)^{1 / 2}\right]^{1 / 3},
$$

and

$$
s_{2}=\left[r-\left(q^{3}+r^{2}\right)^{1 / 2}\right]^{1 / 3}
$$

Then the roots are given by

$$
z_{1}=\left(s_{1}+s_{2}\right)-\frac{a_{2}}{3},
$$

$$
z_{2}=-\frac{1}{2}\left(s_{1}+s_{2}\right)-\frac{a_{2}}{3}+i \frac{\sqrt{3}}{2}\left(s_{1}-s_{2}\right) \text {, }
$$

and

$$
z_{3}=-\frac{1}{2}\left(s_{1}+s_{2}\right)+\frac{a_{2}}{3}-i \frac{\sqrt{3}}{2}\left(s_{1}-s_{2}\right) .
$$


Another useful relation will be

$$
s_{1} s_{2}=-q \text {. }
$$

3. Solution of the Network Equations. The general solution of Eạs. (34) to (36) is of the form

$$
\begin{aligned}
i & =b_{1} e^{-y_{0} t}+b_{2} e^{-\gamma t} \sin \omega t \\
& +b_{3} e^{-\gamma t} \cos \omega t+b_{4}
\end{aligned}
$$

where

$$
\begin{aligned}
& \gamma_{0}=s_{1}+s_{2}-\frac{a_{2}}{3}, \\
& \gamma=\frac{1}{2}\left(s_{1}+s_{2}\right)+\frac{a_{2}}{3},
\end{aligned}
$$

and

$$
\omega=\frac{\sqrt{3}}{2}\left(s_{1}-s_{2}\right)
$$

Since the quantity $a_{2}$ is identified in Eq. (33) as

$$
a_{2}=\rho=\frac{R}{L_{P}\left(1-k^{2}\right)},
$$

we have

$$
\gamma_{0}=2 \gamma-\rho .
$$

Forcing Eq. (45) to satisfy Eqs. (34) through (36) and the appropriate initial values gives expressions for the currents:

$$
\begin{aligned}
i_{P} & =\left(I_{P}-H\right) e^{(2 \gamma-\rho) t}+\frac{H(3 \gamma-\rho)-2 \gamma I_{P}}{\omega} e^{-\gamma t} \sin \omega t \\
& +H e^{-\gamma t} \cos \omega t, \\
i_{S} & =-\left[E+\sqrt{\alpha} I_{P}\left(1-\frac{L_{T}}{L_{S}}\right)\right] e^{(2 \gamma-\rho) t} \\
& +\frac{(3 \gamma-\rho) E+\bar{\alpha} \sqrt{\alpha} I_{P}-\sqrt{\alpha I_{P}}(2 \gamma-\rho) \frac{L_{T}}{L_{S}}}{\omega} e^{-\gamma t \sin \omega t} \\
& +E e^{-\gamma t} \cos \omega t+\sqrt{\alpha} I_{P}\left(1-\frac{L_{T}}{L_{S}}\right)
\end{aligned}
$$

$$
\begin{aligned}
& i_{E}=-\left(F+\frac{L_{T}}{L_{E}} \sqrt{\alpha_{I}}\right) e^{(2 \gamma-\rho) t}
\end{aligned}
$$

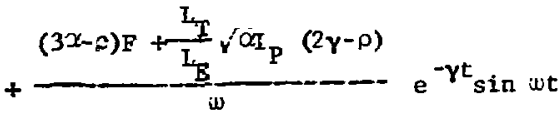

$$
\begin{aligned}
& +\mathrm{Fe}-\mathrm{YT}_{\cos \mathrm{t}}+\sqrt{ } \sigma_{\mathrm{T}} \frac{\mathrm{L}_{\mathrm{T}}}{\mathrm{L}_{\mathrm{E}}},
\end{aligned}
$$

where

$$
\begin{aligned}
& \mathrm{H}=\frac{4 \gamma(2 \gamma-\rho) I_{P}}{(3 \gamma-\rho)^{2}+\omega^{2}}, \\
& E=\frac{(2 \gamma-\rho)\left[(4 \gamma-\rho) \frac{L_{T}}{L_{S}}-4 \gamma\right] \sqrt{S} I_{P}}{(3 \gamma-\rho)^{2}+\omega^{2}},
\end{aligned}
$$

and

$$
F=-\frac{L_{T}}{I_{E}} I_{P} \sqrt{\alpha} \frac{(4 \gamma-\rho)(2 \gamma-\rho)}{(3 \gamma-\rho)^{2}+\omega^{2}}
$$

B. Ratio of $\mathrm{L}_{\mathrm{E}} / \mathrm{L}_{\mathbf{S}}$ for Maximun Transfer Efficiency

The value of $w$ is found by substituting $t=\tau$ into $\frac{d i_{E}}{d t}=0$. The expression for $\frac{d i_{E}}{d t}=0$ is made up of $e^{(2 \gamma-\rho) t}, e^{-\gamma t} \cos \omega t$, and $e^{-\gamma t} \sin w t$ terms since $i_{E}$ contains these terms. Coefficienis of the $e^{(2 \gamma-\rho) t}$ and $e^{-\gamma t} \cos \omega t$ terms are identical, while the coefficient of the $e^{-\gamma t}$ sin wt term is $\beta^{-1}$ of the other two in order of magnitude. Parameter $\beta$ is again defined by

$$
\boldsymbol{\beta}=\frac{\boldsymbol{\omega}}{\boldsymbol{\gamma}}
$$

with $\beta \geq 10$. It will be shown later that we can write $\rho$ as

$$
\rho=\frac{4\left(1-k^{2}\right)}{k^{2}} \beta \omega\left(1+\operatorname{Order} \beta^{-2}\right)
$$

With $\omega=\frac{\pi}{\tau}$ to zero order, the factor $\mathrm{c}^{(2 \gamma-\rho) \tau}$ is 
roughly $\mathrm{e}^{-\beta}$ and negligible compared to the $\mathrm{e}^{-\boldsymbol{\gamma}^{\top}} \sin$ $\omega \tau$ and $e^{-y^{\top}} \cos \omega \tau$ terms. In finding expressions for the various circuit parameters, an expansion in $\beta^{-1}$ will be carried out to order $\beta^{-1}$. The two remaining terms in $\frac{d i_{E}}{d t}=0$ yield the relation

$$
\cot \omega t=\frac{\rho-3 y}{\omega},
$$

which can be expanded to give

$$
\omega=\frac{\pi}{T}\left(1+\frac{4 f}{\pi \beta}\right),
$$

with

$$
f=\frac{\left(1-k^{2}\right)}{k^{2}}
$$

With $C, R, I_{P}, L_{P}, k$, and $I_{S}$ held constant, the value of $L_{E}$ to be selected occurs when

$$
W_{E}=\frac{1}{2} I_{E} i_{E}^{2}(t=T)
$$

is maximized. Equivalently $\sqrt{L_{E}} i_{L}$, can be maximized. From Eqs. (53) and (56)

$$
\sqrt{\mathrm{L}_{\mathrm{E}} i_{E}}=\sqrt{\alpha I_{P}} \frac{\mathrm{I}_{\mathrm{p}}}{\sqrt{\mathrm{I}_{\mathrm{E}}}}\left[1-\frac{(2 \gamma-\rho)}{(3 \gamma-\rho)} \mathrm{e}^{-\gamma^{\tau}} \sin \omega \tau\right]
$$

is a maximun when

$$
\mathrm{L}_{\mathrm{S}}=\mathrm{L}_{\mathrm{E}}
$$

C. Expressions for the Currents when $\mathrm{L}_{S}=\mathrm{L}_{E}$

We assume from now on the $\mathrm{L}_{S}=\mathrm{L}_{E}$ and rewrite Eqs. (51) to (53) using this simplification.

$$
\begin{aligned}
i_{P}= & I_{E}\left[\frac{(\gamma-\rho)^{2}+\omega^{2}}{(3 \gamma-\rho)^{2}+\omega^{2}} e^{(2 \gamma-\rho) t}+\frac{2 \gamma}{\omega}\right. \\
& =\frac{(3 \gamma-\rho)(\gamma-\rho)-\omega^{2}}{(3 \gamma-\rho)^{2}+\omega^{2}} e^{-\gamma t} \sin \omega t \\
& \left.+\frac{4 \gamma(2 \gamma-\rho)}{(3 \gamma-\rho)^{2}+\omega^{2}} e^{-\gamma t} \cos \omega t\right],
\end{aligned}
$$

$$
\begin{aligned}
i_{S} & =\frac{\sqrt{x} \mathrm{I}}{2}\left[1-\frac{2 \rho^{2}+\gamma(\gamma-4 \rho)+w^{2}}{(3 \gamma-\rho)^{2}+\omega^{2}} e^{(2 \gamma-\rho) t}\right. \\
& -\frac{1}{\omega} \cdot \frac{\chi(3 \rho-2 \gamma)(\rho-3 \gamma)-(2 \gamma+\rho) \omega^{2}}{(3 \gamma-\rho)^{2}+\omega^{2}} \mathrm{e}^{-\gamma t} \sin \omega t \\
& +\frac{(\rho-2 \gamma)(\rho+4 \gamma)}{(3 \gamma-\rho)^{2}+2^{2}} \mathrm{e}^{-\gamma t \cos \omega t]}
\end{aligned}
$$

$$
\begin{aligned}
i_{E}= & \frac{\sqrt{\alpha I} P}{2}\left[1-\frac{\gamma^{2}+\omega^{2}}{(3 \gamma-\rho)^{2}+w^{2}} e^{(2 \gamma-\rho) t}-\frac{1}{\omega}\right. \\
& =\frac{(\rho-2 \gamma)\left(\rho \gamma-3 \gamma^{2}+\omega^{2}\right)}{(3 \gamma-\rho)^{2}+\omega^{2}} e^{-\gamma t} \sin \omega t \\
& \left.-\frac{(\rho-4 \gamma)(\rho-2 \gamma)}{(3 \gamma-\rho)^{2}+w^{2}} e^{-\gamma t} \cos \omega t\right]
\end{aligned}
$$

$$
\begin{aligned}
j_{C} & ={\sqrt{C_{I}}}_{P}\left[\frac{\rho(2 \gamma-\rho)}{(3 \gamma-\rho)^{2}+\omega^{2}} e^{(2 \gamma-\rho) t}-\frac{\rho}{\omega}\right. \\
& \cdot \frac{\gamma(\rho-3 \gamma)-\omega^{2}}{(3 \gamma-\rho)^{2}+\omega^{2}} e^{-\gamma t} \sin \omega t \\
& \left.+\frac{\rho(\rho-2 \gamma)}{(3 \gamma-\rho)^{2}+\omega^{2}} e^{-\gamma^{2}} \cos \omega t\right] .
\end{aligned}
$$

Figure 4 shows current in the various circuit elements as a function of time for one choice of circuit parameters. A turns ratio of 10 between the secondary and primary has amplified the peak current in the secondary circuit by about a factor of 10 over the peak current in the primary circuit. Another noteworthy point is the large current spike in $i_{P}$ just after the switch is opened. This current spike will produce a high voltage transient across $R$ and also result in increased energy dissipation in $R$ as shown in Fig. 5. Cause of the spike is the uncoupled inductance $(k=0.95)$ in the primary circuit, and the increased dissipation is essentially the energy stored in the uncoupled inductance. Both Figs. 4 and 5 were generated by numerical integration of Eqs. (33). 


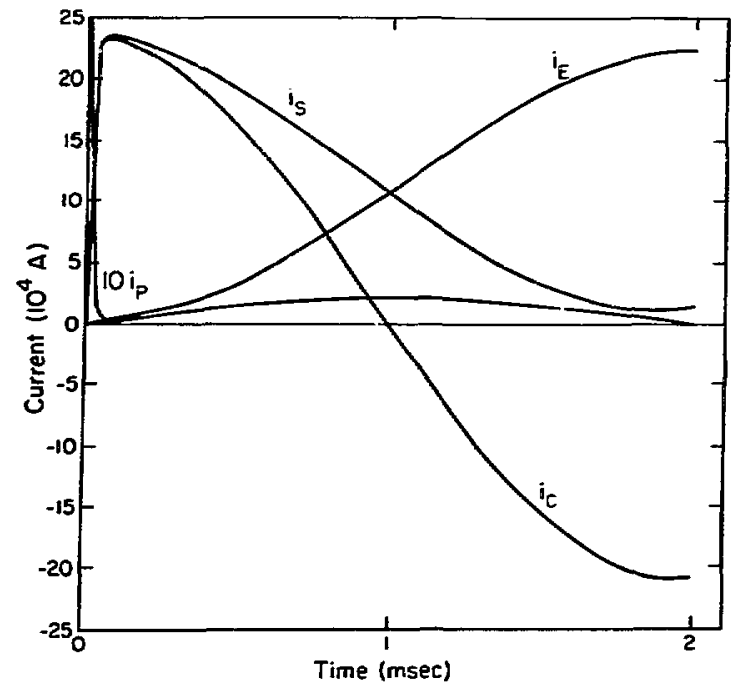

Fig. 4. Current in the circuit elements as a function of time for a transformer coupled system with a transfer capacitor across the load. Circuit parameters are $R=160 \Omega$, $I_{P}=25 \mathrm{kA}, L_{P}=20.4 \mathrm{mH}, L_{S}=L_{E}=204 \mu \mathrm{H}$, $\mathrm{C}=4 \mathrm{mF}$, and $\mathrm{k}=0.95$. A current equal to $10 i_{p}$ has been plotted to expand the scale for ${ }^{P}{ }_{P}$

D. Calculation of $t_{V C}, t_{V R}, R$, and $I_{E}$

The time of maximum voltage across capacitor $C$ is denoted by $t_{V C}$ and is found by setting Eq. (64) for ${ }^{i_{C}}$ equal to zero and solving for $t_{V C}$. The exponential term $e^{(2 \gamma-\rho) t}$ is again neglected, and the result is

$$
t_{V C}=\frac{T}{2}\left[1+\left(\frac{4 E}{\pi}-\frac{2}{\pi}\right) \frac{1}{\beta}\right]
$$

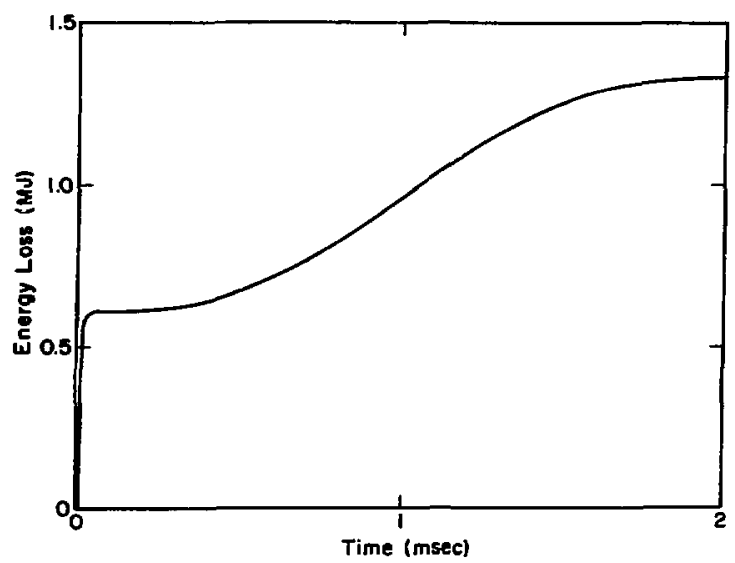

Fig. 5. Total energy loss in $R$ as a function of time for the circuit described in Fig. 4 .
Highest voltage across $R$ occurs at $t=0$ for coupling constant $k<1$, but after dipping to almost zero it builds up to a secondary maximum as seen for example in Fig. 4 at about $t=1 \mathrm{msec}$. Time of the secondary maximum $\left(t_{V P}\right)$ is found by setting $E q$. (61) for $i_{P}$ to zero and solving for $t_{V P}$.

$$
t_{V P}=\frac{T}{2}\left[1+\left(\frac{64}{\pi} f^{2}-\frac{2}{\pi}-\frac{4 f}{\pi}\right) \frac{1}{\beta}\right] .
$$

Using Eq. (51), the voltage across $R$ at $t=t_{V P}$ is $v_{P}=R i_{P}\left(t=t_{V P}\right)$. Actually $v_{P}$ is the given input parameter and this equation is used to find $R$.

$$
R=\frac{V_{P}}{2 I_{P}}\left(\beta+\frac{\pi}{2}\right)
$$

Voltage across $R$ at $t=0$ is given by

$$
v_{P}^{\prime}=\frac{v_{P}}{2}\left(\beta+\frac{\pi}{2}\right) \text {. }
$$

Peak current in $L_{E}$ comes from Eq. (63) evaluated at $t=T$ and is given by

$$
I_{E}={\sqrt{C_{I}}}_{P}\left(1-\frac{\pi}{2 \beta}\right)
$$

\section{E. Calculation of $\mathrm{V}_{\mathrm{C}}, \mathrm{C}, \mathrm{L}_{\mathrm{P}}$, and $\mathrm{L}_{\mathrm{E}}$}

Peak voltage across capacitor $\mathrm{C}$ is denoted by $v_{C}$ and occurs at $t=t_{v C}$. In order to find $v_{C}$, we must relate $v_{C}$ to $v_{0}$ (the voltage across $R$ at $t=t_{v c}$ ); and $v_{0}$ in turn must be related to $v_{P}$ (the voltage across $R$ at $\left.t=t_{V P}\right)$. By using Eq. (61) at the two different times, it can be shown that $v_{p}$ $=v_{0}$, through order $\beta^{-1}$ at least. Then $v_{P}$ is related to $v_{C}$ by

$$
v_{P}=\frac{R i_{P}\left(t=t_{v P}\right)}{L_{E} \frac{d i_{E}\left(t=t_{V C}\right)}{d t}} .
$$

In this equation the currents and their derivatives come from Eqs. (61) and (65), while $R / L_{E}$ is eliminated with Eqs. (38), (39), and (60). The final expression for $\mathrm{V}_{\mathrm{C}}$, good to order $\beta^{-1}$ which vanishes, is

$$
\mathrm{v}_{\mathrm{c}}=\frac{\mathrm{v}_{\mathrm{p}}}{\sqrt{\mathrm{a}}}
$$


Capacitance $\mathrm{C}$ can be related to $V_{\mathrm{C}}$ by

$$
v_{C}=\frac{1}{c} \int_{0}^{t_{v C}} i_{C} d t
$$

Performing the integral and using Eq. (70) yields

$$
\mathbf{C}=\frac{\alpha_{\mathbf{I}_{\mathbf{P}}}{ }^{\top}}{\pi \mathrm{V}_{\mathbf{P}}}\left|1-\left(\frac{\pi}{2}+\frac{4 E}{\pi}\right) \frac{1}{\beta}\right| .
$$

In order to find $h_{p}$, we first use Eqs. (47), (48), and (49) to obtain

$$
\frac{1}{9}\left|(3 \gamma-0)^{2}-3 w^{2}\right|=s_{1} s_{2} .
$$

Eliminating $\mathrm{S}_{1} \mathrm{~S}_{2}$ between Eqs. (72) and (4') finally gives an equation in which $L_{p}$ can be solved for in terms of quantities already calculated. The result is

$$
\mathrm{L}_{\mathrm{P}}=\frac{2 \mathrm{~V}_{\mathrm{P}}{ }^{\top}}{\mathrm{k}^{2} \mathrm{I}_{\mathrm{P}} \pi}\left|1+\left(\frac{\pi}{2}-\frac{4}{T} \mathrm{f}\right) \frac{\mathrm{l}}{\beta}\right|
$$

Equations (38) and (60) then give $L_{S}$ and $L_{E}$ in tems of $L_{p}$. These expressions are given in Table II. With $I_{p}$ known, Eq. (55), which was assuned to be true can now be checked by direct substitution and found to be consistent.

\section{F. Energy Dissipation and Efficiency}

Using Eq. (73) the energy originally stored in $\mathrm{L}_{\mathrm{P}}$ is given by

$$
\begin{aligned}
W_{P} & =\frac{1}{2} L_{P} I_{P}^{2} \\
& \left.=\frac{I_{P} V_{P}{ }^{T}}{\pi k} \mid 1+\left(\frac{\pi}{2}-\frac{4 f}{\pi}\right) \frac{1}{\beta}\right] .
\end{aligned}
$$

Energy delivered to the experiment is

$$
\begin{aligned}
W & =\frac{1}{2} L_{E} I_{E}^{2} \\
& =\frac{I_{P} V_{P}{ }^{\top}}{\pi}\left|1-\left(\frac{\pi}{2}+\frac{4 f}{\pi}\right) \frac{1}{\beta}\right| .
\end{aligned}
$$

Transfar efficiency is given by

$$
\begin{aligned}
E & =\frac{w_{E}}{w_{P}} \\
& =k^{2}\left(1-\frac{\ddot{B}}{B}\right) .
\end{aligned}
$$

It is instructive to leok st the energy loss in resistor $R$ in nore decail. The cotal loss $\left(Q_{\mathrm{RT}}\right)$ ean be approsinately divided into two parts, weh the first part $\left(Q_{\mathrm{tr}}\right)$ due to the uneoupled induetante in the primary cireuit, while the sccond part $\left(Q_{R}\right)$ /s due to the voltage indued in the prinary elreate by changing current in $L_{S}$. The total loss is giten by

$$
Q_{R T}=\left(1-k^{2}\right) \frac{v_{p} I_{p}^{T}}{: k^{2}}\left(1+\left(\frac{\dot{\bar{t}}}{2}-\frac{4 f}{\vdots}\right) \frac{1}{\beta}\right) \div \frac{v_{p} I_{p}}{B} \text {. }
$$

where the first tere on the right is identified wich $Q_{U: S}$ and the second fo itentified sith $Q_{R}$. To order $p^{-1}$ it can be seen that

$$
Q_{U S}=\frac{1}{2}\left(1-k^{2}\right) L_{y^{2}}^{2}
$$

There is sone diffieuley in earytng this divtgion of energy loss to order $\beta^{-2}$ beeause cross terms oecur in $i_{P}{ }^{2}$ between the $c^{(2 \gamma-p) \div}$ cem and the osell. lintory terns. These cross tersis are of order $p^{-2}$ and could reasonably be fnciuded in cicher $Q_{\mathrm{LN}_{\mathrm{N}}}$ or $\boldsymbol{Q}_{\mathrm{R}}$. Ineluding these terms in $Q_{n}$ allows $Q_{R}$ to bo cateled one order farther.

$$
Q_{R}=\frac{V_{P^{I} p^{\top}}}{\beta}\left[1-\frac{1}{\beta}\left(\frac{2}{2}+\frac{4 f}{2}+\frac{32 f^{2}}{q}\right)\right] .
$$

Sinec the $\beta^{-2}$ tems in $Q_{\text {ux }}$ originating fren $R$ have not been calculated, we cannot tell if $Q_{R T}$ is nore accurate inelsding the $\beta^{-2}$ torm in $Q_{R}$ or vicheut $l \varepsilon$. Encrgy remaining in $L_{S}$ at $t=$ i can be show to be of order $\beta^{-2}$, and energy in $k_{p}$ and fa the sutual laduecance belongs to still higher ordex.

G. Hadule iengeh, Nimber of Turns, and Magnet fe Ficld strength

Fran Eqs. (4) and (75) the nedule length is

$$
i=\frac{I_{p} V_{p}^{\top}}{A^{\top}}\left|1-\left(\frac{E}{2}+\frac{4 E}{E}\right)_{\beta}^{\frac{1}{\beta}}\right| .
$$


Paraexer

coupling censesne

Farameter

Time of pak voltafe across $($ (sec)

Tine of highese toltage seross $h$ excluding inletel trantient (sec)

Capacteance (F)

Rostetance (i)

Indwetante of $t p$ (it)

Induecance of $\mathrm{L}_{\mathrm{E}}$ and $\mathrm{t}_{\mathrm{s}}$ (II)

Peak volcage acrass $G$ (U)

Peak eurrent in $t(x)$

Energy Ecansforted $20 \mathrm{~L}_{\mathrm{E}}(x)$

Energy In uncoupled inductance ( $)$

Energy qose in $R$ excluding $Q_{\text {un }}$ (3)

Energy seored in $!_{p}(J)$

Efeictency

rodule lengeh (cm)

Nuber of curns on $\mathrm{k}_{\mathrm{E}}$
Evuseian

$$
\begin{aligned}
& k-\frac{r_{p}}{E_{p}+s} \\
& f=\frac{1-k^{2}}{k^{2}}
\end{aligned}
$$

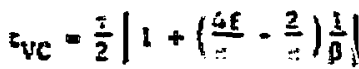$$
c_{v p}=\frac{\pi}{2}\left[1+\left(\frac{64}{4} f^{2}-\frac{f}{2}-\frac{4 E}{n}\right) \frac{1}{p}\right)
$$

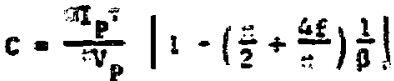$$
n=\frac{v_{p}}{2 \tau_{p}} \rho\left|+\frac{z}{2 \beta}\right|
$$$$
L_{p}=\frac{2 v_{p}^{T}}{-k^{2} I_{P}}\left|1+\left(\frac{E}{2}-\frac{4 f}{t}\right) \frac{1}{\beta}\right|
$$

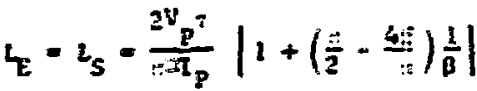$$
v_{c}-\frac{v_{p}}{7 x}
$$$$
I_{E}-\gamma 1_{p}\left(1-\frac{z}{2 \beta}\right)
$$

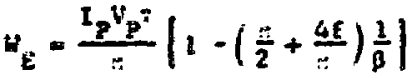

$q_{\mathrm{g}}=\frac{\left(1-k^{2}\right) v_{p^{2} p^{T}}}{-k^{2}}\left|1+\left(\frac{5}{2}-\frac{4 E}{n}\right) \frac{1}{\beta}\right|$

$Q_{n}=\frac{v_{p^{I}}{ }^{T}}{p}$

$\omega_{p}=\frac{\tau_{p} V_{p}^{T}}{t k^{2}}\left|1+\left(\frac{r}{2}-\frac{4 E}{t}\right) \frac{1}{p}\right|$

$c=k^{2}\left(1-\frac{\pi}{b}\right)$

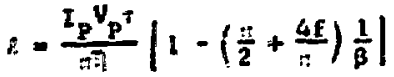

$n_{E}=\frac{V_{p}^{i}}{i t} \sqrt{\frac{2}{a F^{F}}}\left(1-\frac{4 f}{i \beta}\right)$ 


$$
\begin{aligned}
& \text { Rodius of secondary (cm) } \quad r_{S}=r_{P}+\Delta \\
& \text { Number of turns on } \mathrm{L}_{\mathrm{S}} \\
& n_{S}=\frac{\sqrt{5 \times 10^{4}}}{2} \cdot \frac{v_{P}}{\left(r_{P}+\Delta\right) \sqrt{\alpha}}\left(1-\frac{4 f}{\pi \beta}\right) \\
& \text { Inftial field in } L_{p}(G) \\
& B_{P}=\frac{\sqrt{8 \times 10^{7} \eta}}{I_{P^{k}}}\left(1+\frac{\pi}{2 \beta}\right) \\
& n_{P}=\frac{\sqrt{5} \times 10^{4}}{\pi^{2}} \cdot \frac{V_{p}}{r_{P} k \sqrt{\pi}}\left(1-\frac{4 f}{\pi \beta}\right) \\
& \mathrm{V}_{P}^{\prime}=\frac{\beta \mathrm{V}_{\mathrm{P}}}{2}\left(1+\frac{\pi}{2 \beta}\right)
\end{aligned}
$$

The number of turns on the experiment coil is found from Eqs. (2), (38), and (73) and is given by

$$
n_{E}=\frac{v_{P}^{T}}{\pi} \sqrt{\frac{2}{\alpha n !}}\left(1-\frac{4 f}{\pi \beta}\right) .
$$

Again at this point another input parameter must be chosen, and the parameter chosen is $r_{P}$, the radius of the storage coil in $\mathrm{cm}$. The secondary coil radius can now be found from

$$
\frac{r_{S}}{r_{p}}=\frac{1}{k} .
$$

Alternatively, if the difference between $r_{S}$ and $r_{P}$ is taken to be a constant $(\Delta)$, then

$$
\mathbf{r}_{\mathbf{S}}=\mathbf{r}_{\mathbf{p}}+\Delta,
$$

and the coupling constant can be calculated from

$$
k=\frac{r_{P}}{r_{P}+\Delta} .
$$

When $r_{S}$ is known, the number of turns on the secondary $\left(n_{s}\right)$ is decermined because

$$
\frac{n_{S}}{n_{E}}=\frac{r_{E}}{r_{S}} \text {. }
$$

Substituting Eqs. (2), (79), and (80) into Eq. (82) gives

$$
n_{S}=\frac{\sqrt{5} \times 10^{4} v_{P}}{\pi^{2}\left(r_{P}+\Delta\right) \sqrt{a m}}\left(1-\frac{4 f}{\pi \beta}\right) .
$$

Initial magnetic field in the primary is calculated from Eq. (3) and given by

$$
{ }^{B} P=\frac{\sqrt{8 \times 10^{7} \eta}}{\mathrm{kr}_{P}}\left(1+\frac{\pi}{2 \beta}\right)
$$

The number of turns on the storage $\operatorname{coil}\left(n_{p}\right)$ can be found using Eq. (31), and the result is

$$
n_{P}=\frac{\sqrt{5} \times 10^{4} v_{P}}{\pi^{2} r_{P} k \sqrt{\pi}}\left(1-\frac{4 f}{\pi g}\right) .
$$

\section{H. Method for Obtaining Approximate Results}

Setting $k=1$ in Eqs. (33) reduces the order of the differential equations to be solved fram third order to second order, and the problem is then similar to the direct coupled case. In solving the second order equations, initial values to be taken at $t=0$ are: $i_{E}=i_{P}=0, i_{S}=\sqrt{\alpha_{I}}$, and

$\frac{d i_{E}}{d t}=\frac{d i_{P}}{d t}=\frac{d i_{S}}{d t}=0$. Resulting equations for the currents are: 


$$
\begin{aligned}
& i_{E}=\sqrt{ } \alpha I_{P} \frac{L_{S}}{L_{S}+I_{E}}\left(1-e^{-\gamma t} \cos \omega t-\frac{\partial}{x} e^{-\gamma t} \sin \perp t\right), \\
& i_{S}=\sqrt{C} I_{P} \frac{L_{E}}{L_{S}+I_{E}}\left[\frac{L_{S}}{L_{E}}+e^{-\gamma t} \cos L t-\frac{Y}{L}\left(1+\frac{2 L_{S}}{L_{E}}\right) e^{-\gamma t} \sin \nu t\right],
\end{aligned}
$$

$$
i_{C}=\sqrt{\alpha} I_{P}\left(e^{-\gamma t} \cos \omega t-{ }_{D}^{\chi} e^{-\gamma t} \sin \omega t\right),
$$

and

$$
I_{P}=2 I_{P} \frac{\gamma}{w} e^{-\gamma t} \sin \omega t
$$

where

$$
y=\frac{\alpha}{2 \mathrm{RC}}
$$

and

$$
\omega=\sqrt{\frac{L_{E}+L_{S}}{L_{E} L_{S} C}-\gamma^{2}} .
$$

If the additional approxination $e^{-\gamma c}=I$ is made, the expressions for the various circuit parmeters become especially simple. Maximum energy transfer to $\mathrm{L}_{\mathrm{E}}$ occurs again when $\mathrm{L}_{\mathrm{E}}=\mathrm{L}_{\mathrm{S}}$.

Heuristic arguments can then extend the results to the $k<1$ case. Energy stored in the uncoupled primary inductance is

$$
Q_{\mathrm{UN}}=\frac{1}{2}\left(1-k^{2}\right) \mathrm{L}_{\mathrm{P}} \mathrm{I}_{\mathrm{P}}^{2} \text {, }
$$

and this energy is dumped in $R$ as an initial cransient. Energy coupled through the transformer is

$$
W_{C O}=\frac{1}{2} k^{2} L_{P} I_{P}^{2}
$$

which suggests that the ratio of both $Q_{R}$ and $W_{E}$ to $W_{P}$ must be reduced by a factor $k^{2}$ in going to the $k<1$ case. Finally, the factor $k^{2}$ must be included in the definition of $\alpha$ so that for all expressions

$$
\alpha=k^{2} \frac{L_{p}}{L_{S}} \text {. }
$$

The quantity if thust be wied in:tead of $\sqrt{\frac{1}{l_{3}}}$ co conpute prisary voltage from secondary is thate, ctc.

\section{Sursary}

Table II stroarizes the quantitics thich thave been calculated for eircuit (b) of Fig. 2 frow the given set of input parateters. These input paraxeters are: the inftial current in the prirary in anpercs $\left(I_{p}\right)$, the radius of the prifary in $c a\left(\varepsilon_{p}\right)$, the differenee between the prinary and sccondary radius in co (D), the naxinum voltage across the prinury excluding the infitial transient $\left(v_{p}\right)$, the transfur time to the experinent in seconds ( $T$ ), the ratio of the daping constant to angular frequency $(\beta)$, a constane equal to the calculated coupling constant squared times the inductance ratio of the prinary and secondary $(\infty)$, the energy delivercd to the experiment per unit length in $\mathrm{J} / \mathrm{co}(\mathrm{T})$, and an inductance constant for the experinent coil in $\| 1-c r / s u r n^{2}(\xi)$.

v. TRANSFORYER COUPLING OF STORAGE COIL AND EXEERIRENT UITH A TRANSFER CAPACITOR ACROSS THE TRANSFORMER PRIMARY

\section{A. Circuite Parameters}

The network equations for circuit (c) of Fig. 2 can be written as:

$$
\begin{aligned}
& \left(I_{E}+L_{S}\right) \frac{d i_{S}}{d t}+k \sqrt{L_{P} L_{S}} \frac{d i_{P}}{d t}=0, \\
& L_{P} \frac{d i_{P}}{d t}+R i_{R}+k \sqrt{L_{P} L_{S}} \frac{d i_{S}}{d t}=0,
\end{aligned}
$$

and

$$
C R \frac{d i_{R}}{d t}-i_{P}+i_{R}=0 .
$$

If we take $L_{E}=L_{S}$, the currents in the various circuit elements can be written as

$$
t_{P}=I_{P} e^{-\gamma t}\left(\cos \omega t+\frac{Y}{\omega} \sin \omega t\right)
$$




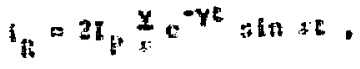

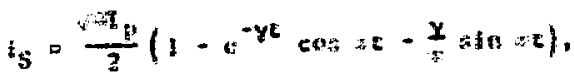

ans

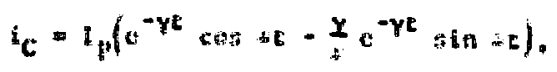

were

$$
\begin{aligned}
& y=\frac{1}{2 R C} . \\
& +\int_{l_{p} c\left(1-\frac{k^{3}}{2}\right)}-\gamma^{2}
\end{aligned}
$$

and

$$
x=k^{2} \frac{L_{p}}{t_{s}}
$$

Peak eurrent oceurs in $L_{E}$ when $:=\frac{L}{D}$. Details of the resalinder of the calculation are sint lar to those of the direct coupled circuit, and so only the results are given in Table 111. The definitions of elu tuput parameters are the sane in Tabic III as in Table II. Expansions in $\beta^{-1}$ are corricd out to order $\beta^{-2}$.

\section{B. lincoupled Inductance}

Energy loss from the uncoupled induetance requires some explonation because it takes a different form in circuit (c) than In circuit (b). Figure 6 shows the current in the various eircuit elements as a function of time in circuit (c) for a particular choice of paraneters. Although $k=0.95$, the fnitial voltage transient across $\hat{k}$ found in circuit (b) does not occur nor does Fig. 7 show any transient encrgy loss. When the crowbar is applied at $t=\tau$, the uncoupled energy is stored in the transformer. The capacitor is completely discharged at that time. For $c>T$, there will be oscillations between $C$ and the uncoupled inductance, with most of the uncoupled encrgy gradually lost in $R$ and lead resistance. A second crowbar across capacitor $C$ might be useful to damp the oscillations and prevent energy loss in $k$

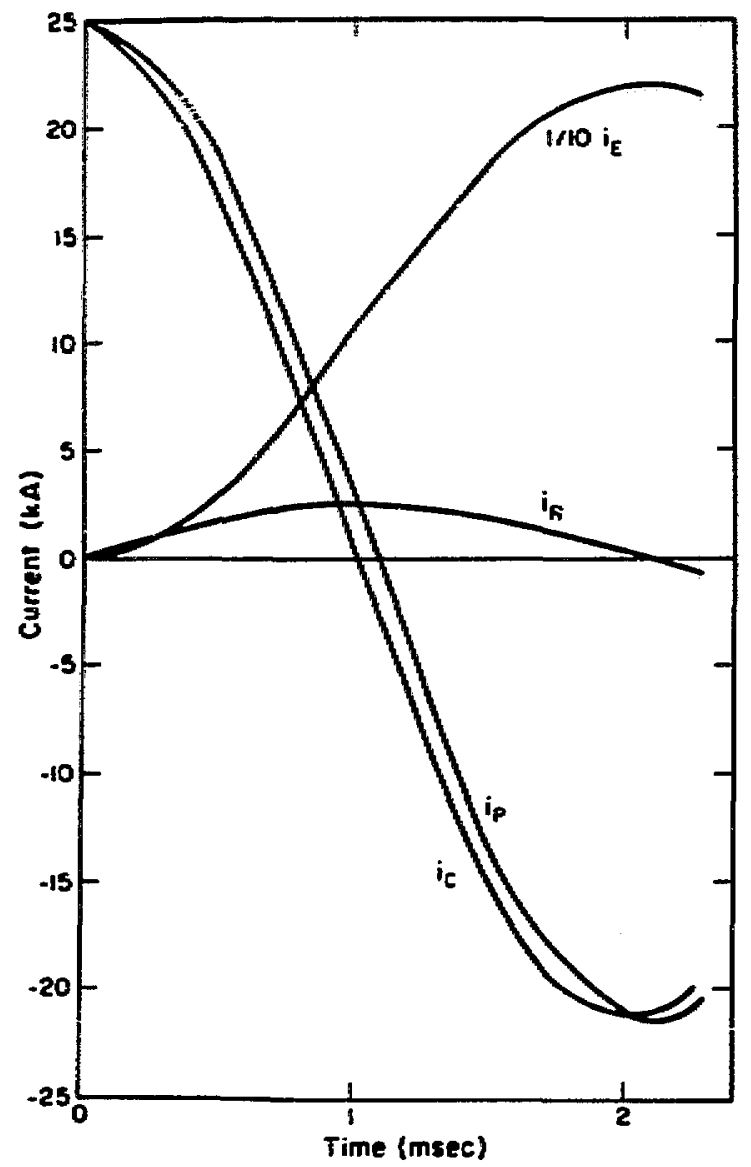

Fig. 6. Current in the circuit elements as a function of titue for a transformer coupled systen with a transfer capacitor across the storage coil. Circuit parameters are $R=16 S_{1}, I_{P}=25 \mathrm{kA}, L_{P}=2 \mathrm{mH}, L_{S}=L_{E}$ current equal to $0.1 i_{E}$ has been plotted to fit it on the graph.

and the dewar leads. Referring to Fig. 6 again, it should be noted that when the crowbar is applied there are high currents flowing in both $L_{P}$ and $L_{S}$. The direction of the currents is such that the magnetic fields tend to cancel and reduce the amount of stored energy.

The energy not coupled into $L_{E}$ at $t=T$ is listed in Table $I I$ as $Q_{\mathrm{UN}}$. It requires a more careful examination to see what part of this energy is lost in $R$ and what part is coupled into the secondary. If the crowbar switch is assumed to have no resistance and is closed at $t=T$, the energy loss in $R$ as $t \rightarrow \infty$ can be shown to be 
CAUCULATED PARALETERS FOR A TRAHSFORHER COUPLED MAGNETIC ENERGY STORAGE SYSTEY WITH A TRAUSFER CAPACITOR ACROSS THE TRANSFORHER PRIHARY

\section{Parameter}

\section{Equation}

Coupling constant

Time of peak voltage across $I_{p}$ (sec)

Tiwe of peak vol tage across $L_{E}$ (sec)

Capacitance (F)

Resistance (a)

Inductance of $L_{P}(H)$

Inductance of $L_{S}$ and $I_{E}(H)$

Peak voltage across $I_{E}(V)$

Peak current in $I_{E}$ (A)

Energy transferred to $L_{E}$ (J)

Energy not coupled into $L_{E}$ at $\mathrm{t}=\tau(\mathrm{J})$

Energy stored in $I_{P}(J)$

Efficiency

Module length (cm)
$k=\frac{r_{p}}{r_{p}+\Delta}$

$v_{v P}=\frac{\tau}{2}\left(1-\frac{2}{: \beta}\right)$

$t_{\mathrm{VE}}=\frac{\pi}{2}\left(1-\frac{2}{\pi \beta}\right)$

$C=\frac{I_{P} T}{V_{P} T}\left[l-\frac{\pi}{2 \beta}+\left(\frac{T^{2}}{8}+\frac{1}{2}\right) \frac{1}{\beta}\right]$

$R=\frac{V_{P}^{\beta}}{2 I_{P}}\left[1+\frac{\pi}{2 \beta}+\left(\frac{\pi^{2}}{8}-\frac{1}{2}\right) \frac{1}{\beta^{2}}\right]$

$L_{P}=\frac{2 \tau V_{p}}{\left(2-k^{2}\right)_{\pi I}}\left[1+\frac{\pi}{2 \beta}+\left(\frac{\pi^{2}}{8}-\frac{3}{2}\right) \frac{1}{\beta^{2}}\right]$

$I_{S}=L_{E}=\frac{2 k^{2} \tau V_{p}}{\left(2-k^{2}\right)+0 I_{P}}\left[1+\frac{\pi}{2 \beta}+\left(\frac{\pi^{2}}{8}-\frac{3}{2}\right) \frac{1}{\beta}\right]$

$v_{E}=\frac{k^{2} v_{P}}{\left(2-k^{2}\right) \sqrt{\alpha}}$

$I_{E}=\sqrt{\alpha} I_{P}\left(1-\frac{\pi}{2 \beta}+\frac{\pi^{2}}{4 \beta^{2}}\right)$

$W_{E}=\frac{k^{2} \tau V_{P} I_{P}}{\left(2-k^{2}\right)_{\pi}}\left[1-\frac{\pi}{2 \beta}+\left(\frac{3 \pi^{2}}{8}-\frac{3}{2}\right) \frac{1}{\beta^{2}}\right]$

$Q_{U N}=\frac{\left(1-k^{2}\right) \tau V_{P} I_{P}}{\left(2-k^{2}\right)_{\pi}}\left[1-\frac{3 \pi}{2 \beta}+\left(\frac{7 \pi^{2}}{8}-\frac{3}{2}+\frac{\pi^{2}}{4\left(1-k^{2}\right)}\right) \frac{1}{\beta^{2}}\right]$

$W_{P}=\frac{\tau V_{P} I_{P}}{\left(2-k^{2}\right)_{\pi}}\left[1+\frac{\pi}{2 \beta}+\left(\frac{\pi^{2}}{8}-\frac{3}{2}\right) \frac{1}{\beta}\right]$

$\varepsilon=k^{2}\left(1-\frac{\pi}{\beta}+\frac{3 \pi^{2}}{4 \beta^{2}}\right)$

$\ell=\frac{k^{2} \pi P_{P} I_{P}}{\left(2-k^{2}\right)_{\pi \eta}}\left[1-\frac{\pi}{2 \beta}+\left(\frac{3 \pi}{8}-\frac{3}{2}\right) \frac{1}{\beta}{ }^{2}\right]$ 
Number of turns on $\mathrm{L}_{\mathfrak{E}}$

Radi us of secondary (cm)

Nember of turns on $L_{S}$

Initial field in $L_{p}(G)$

Number of turns on $t_{p}$
$n_{E}=\frac{k^{2} g_{E}}{\left(z-k^{2}\right) r} \sqrt{\frac{2}{N g}}\left[1+\left(\frac{z^{2}}{8}-\frac{3}{2}\right) \frac{1}{\beta^{2}}\right]$

$\mathbf{r}_{\mathbf{S}}=\mathbf{r}_{\mathbf{P}}+\dot{i}$

$n_{S}=\frac{i \sin 10^{4}}{\pi^{2}} \frac{k^{2}}{\left.! 2-k^{2}\right)} \frac{v_{P^{T}}}{\left|r_{p}+4 \cdot \pi\right|}\left[1+\left(\frac{\pi^{2}}{8}-\frac{3}{2}\right) \frac{1}{\beta^{2}}\right]$

$B_{P}=\frac{\sqrt{8 \times 10^{7}}}{r_{p}}\left(1+\frac{\pi}{2 \beta}\right)$

$\mathrm{n}_{\mathrm{p}}=\frac{\sqrt{5 \times 10^{4}}}{\pi^{2}} \frac{k v_{\mathrm{p}} \mathrm{r}}{\left(2-\mathrm{k}^{2}\right)^{\sqrt{T_{i}}}}\left[1+\left(\frac{\pi^{2}}{8}-\frac{3}{2}\right) \frac{1}{\beta^{2}}\right]$

$$
Q_{R}=\frac{\left(1-k^{2}\right)}{\left(2-k^{2}\right)} \frac{V_{p} I_{P} \tau}{\pi}\left[1-\frac{3 \pi}{2 \beta}+\left(\frac{9 \pi^{2}}{8}-\frac{3}{2}\right) \frac{1}{\beta}\right]
$$

Energy finally trapped in the transformer secondary as $t \rightarrow \infty$ is

$$
Q_{S}=\frac{k^{2}}{\left(2-k^{2}\right)} \frac{I_{p} V_{P}^{T}}{\pi} \cdot \frac{\pi^{2}}{4 \beta^{2}} \cdot
$$

Thus for practical purposes all of $Q_{\mathrm{UN}}$ is lost in the primary, and this would continue to be the case If the crowbar had resistance, provided the crowbar resistance was small enough compared to $R$.

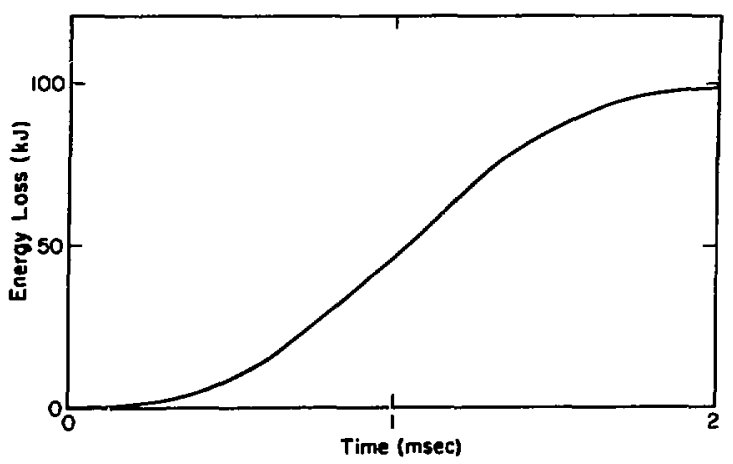

Fig. 7. Total energy loss in $R$ as a function of time for the circuit described in Fig. 6 .
VI. COHPARISON OF THE THREE CIRCUITS

A. Econoraics

In the transformer coupled systems one extra cost item is, of course, the transformer secondary. The transformer gives the ability to step-up current, but it is not imediately obvious that this is much of an advantage. Without doubt the transformer system has imperfect coupling between the secondary and primary. In both transformer coupled circuits this represents energy which is wasted; in circuit (b) it is also energy which is inevitably dissipated at cryogenic temperatures. Another problem peculiar to the transformer systems is the large forces which can exist between the primary and secondary during energy transfer. These forces will exist if there is any misalignment between the primary and secondary, and wi 11 necessitate a stronger and more expensive dewar as we11 as extra bracing structure to support the secondary.

In a practical energy storage system, the individual modules would be slightly rearranged so that the switches and storage coils would be connected in series. Each storage coil would be separated from the next by one of the superconducting switches. With this arrangement, a minimum of only 2 high current leads entering the cryostat is needed to charge up the system. This arrangement might be realized with circuit (b), since it thermally isolates the primary and secondary circuit and couples thein on?y 
magnetically. However, both circuits (a) and (c) have high current leads entering the cryostat every module. These leads cause enhanced heat leak, a1though they could be designed for transient or-tration and have a small cross aection.

As long as $k<1$, circuit (b) has a large voltage transient appearing across the switch just as it is opened. One possible way to cut the transient down might be to insiall extra capacitors across $R$. Another way would be to redice the module length, and hence the size of the voltage transient until the peak yoltage was within safe limits. This would increase the number of modules beyond the optimum number, and the cost of the entire system would increase.

\section{B. Safety}

An adequate discussion of safety in these circuits would mean a calculation of energy deposition In the varlous circuit elements, nct only for normal circuit operation, but for the more probable ma1functions as vell. Unfortunately, this energy daposition depends upon many parameters which were ignorable until now, such as the resistance of the crowbar switch and the bus bar. Because the number and possible range of these parameters is large, we will derive only approximate results for the most likely parameter ranges and consider only two problems. These problems are the ultimate destination of the energy transferred to $L_{E}$ during normal circuit operation and the destination of energy in $L_{P}$ in the event of a crowbar prefire. A conplete failure of the crowbar to fire would be whother malfunction which could be Investigated, but presumably a proper duplication of firing circuits could make this an unlikely occurrence.

1. Transformer Coupled Systems. The principal concern with a crowbar prefire in a transformer coupled system is the amount of energy deposited in the primary circuit because the primary is at low temperature. The given transformer system can be replaced by a circuit in which the secondary is removed and a resistance equal to $\frac{\mathrm{I}_{\mathrm{P}}}{\mathrm{L}_{S}} R_{C B}$ is put in parallel with $R$ across the primary circuit. Here $\mathrm{R}_{\mathrm{CB}}$ is the resistance of the crowbar, and the coupling is taken as $k=1$. When this substitution is made and if $\frac{\mathrm{I}_{\mathrm{p}}}{\mathrm{I}_{\mathrm{S}}} \mathrm{R}_{\mathrm{CB}} \ll R$, the energy lost in $\mathrm{R}$ is of the order

$$
Q_{R}=\frac{\mathrm{L}_{\mathrm{P}}^{\mathrm{R}} \mathrm{CB}}{\mathrm{L}_{\mathrm{S}} \mathrm{R}}\left(\frac{1}{2} \mathrm{~L}_{\mathrm{P}_{\mathrm{P}}}{ }^{2}\right)
$$

Reasonable parameters to use in Eq. (90) are

$\frac{L_{P}}{L_{S}}=100, R_{C B}=0.01$, and $R=100$. With these parameters no more than about $1 \%$ of the energy stored in $L_{P}$ at the time of a croubar prefire should be added to $R$ after the prefire. Physically what happens is that the low impedance of the crowbar allows current to transfer very rapidly from the primary to the secondary circuit. From the type of argunent given to establish $\mathrm{E}_{\mathrm{q}}$. (90), the sane equation should also serve to estimate the energy fed back to $\mathrm{I}_{P}$ from $\mathrm{I}_{\mathrm{E}}$ during normal circuit operation.

2. Direct Coupled System. One reas on that the transformer coupled system turned out to be so safe during crowbar prefire was that resistor $R$ was effectively connected in series with $L_{P}$ for $t \gg t_{C_{B}}$. This limited the amount of current which could flow in the primary circuit. In the direct coupled circuit, $R$ is in parallel with $R_{C B}$ and $I_{P}$ - The concern now is not that excessive energy would be deposited in $R$, but that it would be deposited in the dewar leads or co: : $L_{P}$ if it should be driven normal. Both the crowbar failure and the final disposition of stored energy can be studied with the circuit of Fig. 8. For a crowbar failure at $t=0$ or the decay of energy from the experiment coil during normal operation for $t>\tau$, the low resistance of the crowbar prevents any large voltage from building up across the capacitor. For this reason capacitor $C$ and resistor $R$ can be left out of the circuit in these two situations. In the crowbar case, $\mathrm{L}_{X}$ is the storage

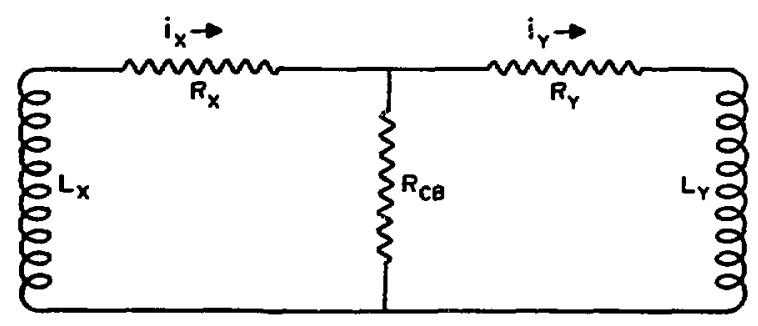

Fig. 8. Simplified circuit used to consider safety problems in direct coupled magnetic energy storage systems. 
coil inductance, $R_{X}$ is the resistance of dewar leads and bus bar, $R_{Y}$ is the resistance of the experiment coil and $\mathrm{L}_{\mathrm{Y}}$ is the experiment coil inductance. For finding the final energy deposition in normal cperation, the storage coil and experiment coil change places so that $\mathrm{I}_{\mathrm{X}}$ is the experiment coil inductance, $\mathrm{L}_{\mathrm{Y}}$ is the storage coil inductance, etc. In either case the initial conditions are $i_{X}=I_{P}$ and $i_{Y}=0$. The inductances are taken as equal, so $L_{X}=I_{Y}=L$. Energy loss in $R_{X}$ and $R_{Y}$ is given by

\section{ACKAOWLEDGIENTS}

We rould like to thank H. L. Laquer for encouragement to reinvestigate the use of transfer capacitors in magnetic energy storage systems, and

J. D. Rogers for many helpful discussions.

$$
Q_{X}=\left(\frac{1}{2} L_{P}{ }^{2}\right) \frac{R_{X}}{\left(R_{X}-R_{Y}\right)^{2}+4 R_{C B}{ }^{2}}\left[\frac{\left(R_{Y}+R_{C B}\right)\left(R_{Y}-R_{X}\right)^{2}+R_{C B}{ }^{2}\left(3 R_{Y}-R_{X}+2 R_{C B}\right)}{R_{X} R_{Y}+R_{C B}\left(R_{X}+R_{Y}\right)}+\frac{4 R_{C B}^{2}}{R_{X}+R_{Y}+2 R_{C B}}\right]
$$

and

$$
Q_{Y}=\left(\frac{1}{2} L I_{P}\right)^{2} \frac{R_{C B}{ }^{2} R_{Y}}{\left(R_{X}-R_{Y}\right)^{2}+4 B_{C B}{ }^{2}}\left[\frac{R_{X}+R_{Y}+2 R_{C B}}{R_{X} R_{Y}+R_{C B}\left(R_{X}+R_{Y}\right)}-\frac{4}{R_{X}+R_{Y}+2 R_{C B}}\right]
$$

Qualitatively, the dangerous situation during a crowbar failure occurs when $R_{X} \gg R_{C B}$, since most of the stored energy will be dumped into the dewar leads $\left(R_{X}\right)$. $Q_{X}$ measures the energy dumped into the dewar leads. During normal decay of current in the storage coil (now $\mathrm{L}_{X}$ ), the dewar leads (now $\mathrm{R}_{\mathrm{Y}}$ ) would receive most of the energy only if $R_{C B} \gg R_{Y}$ $\gg R_{X}$. This is an unlikely situation; however, a significant amount of energy could still be deposited in the leads, and the amount can be calculated from $E q$. (92) for $Q_{Y}$.

A crosbar prefire is more probable at $t=T / 2$ than at $\mathrm{t}=0$ because voltage across the crowbar is maximum at $t=T / 2$ and zero at $t=0$. The circuit of Fig. 8 can also be used to find the energy lost in the dewar leads during a $t=\tau / 2$ prefire if $R_{C B} C \ll L / R_{X}$ and $R_{C B} C \ll L / R_{Y}$. Energy stored in the capacitor just before the prefire is $1 / 2$ of the energy originally stored in $L_{X}$. With the assumed ordering of time constants, all of the energy stored in $\mathrm{C}$ is dissipated in $\mathrm{R}_{\mathrm{CB}}$ before the current has time to change much in $\mathrm{I}_{X}$ and $\mathrm{L}_{\mathrm{Y}^{*}}$ The proper initial values for $i_{X}$ and $i_{Y}$ are now $i_{X}=I_{P} / 2$. Energy deposited in the dewar leads is

$$
O_{X}=\left(\frac{1}{2} L_{P}^{2}\right) \frac{R_{X}}{4\left[\left(R_{X}-R_{Y}\right)^{2}+4 R_{C B}^{2}\right]}\left[\frac{\left(R_{X}-R_{Y}\right)^{2}\left(R_{Y}+2 R_{C B}\right)+8 R_{C B}{ }^{3}+2 R_{C B}{ }^{2}\left(3 R_{Y}-R_{X}\right)-R_{C B}\left(R_{X}{ }^{2}-R_{Y}{ }^{2}\right)}{R_{X} R_{Y}+R_{C B}\left(R_{X}+R_{Y}\right)}+\frac{4 R_{C B}\left(R_{X}-R_{Y}\right)}{R_{X}+R_{Y}+2 R_{C B}}\right]
$$

\section{REFERENCES}

1. F. L. Ríbe, Bu11. Am. Phys. Soc. 16, 1290 (1971). See a1so Los Alamos Scientific Laboratory Report LA-4828-MS, 1971.

2. H. L. Laquer, J.D.G. Lindsay, E. M. Little, J. D. Rogers, and D. M. Weldon, 1972 Texas Symposium on the Technology of Controlled Thermonuclear Fusion Experiments and the Engineering Aspects of Fusion Reactors, Proceedings. See also Los Alamos Scientific Iaboratory Report LA-5314-MS, 1973.

3. R. Carruthers, Proc. I.E. ., Pt. A. Supp. 106, 166 (1959).

4. Milton Abromowitz and Irene A. Segun, Handbook of Mathematical Functions (Dover Publications, Inc., New York, 1965), P. 17. 